\title{
latrogenic pulmonary air embolism
}

\author{
Shannon M. Fernando MD MSc, Peter M. Munene MDCM, Elena Pena MD
}

Cite as: CMAJ 2017 August 21;189:E1069. doi: 10.1503/cmaj.170265
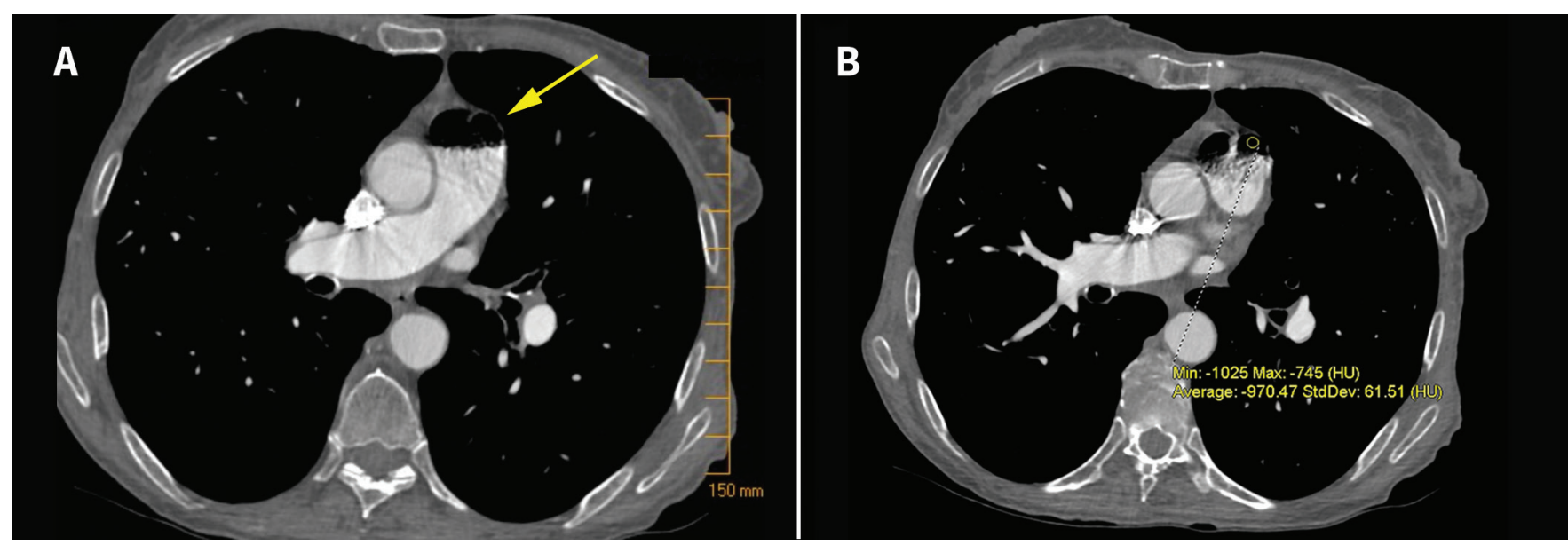

Figure 1: (A) Venous air embolism (yellow arrow) in the main pulmonary artery of a 64-year-old woman, as depicted on the axial view of chest computed tomography. (B) Region of interest shows negative values of about -1000 in Hounsfield units (HU), consistent with air attenuation.

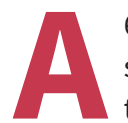

64-year-old woman with a history of lung cancer and severe chronic obstructive pulmonary disease presented to the emergency department with a one-day history of shortness of breath on exertion and pleuritic chest pain. She was tachycardic and required $4 \mathrm{~L} / \mathrm{min}$ of supplemental oxygen at rest. Computed tomography (CT) of the chest was performed with intravenous contrast to rule out possible pulmonary embolism. CT showed no pulmonary embolism, but a venous air embolism was seen in the main pulmonary artery, just above the pulmonic valve (Figure 1 ). It measured about $2.1 \times 2 \times 1.5 \mathrm{~cm}$. A hyperbaric chamber was not available, but because the patient remained hemodynamically stable, the decision was made to monitor her closely and repeat CT in 24 hours. The patient was maintained in the supine position. Repeat CT showed interval resolution of the air embolism. A nasopharyngeal swab performed on arrival was negative for influenza, and progression of her underlying lung disease was thought to be the likely cause for her dyspnea on presentation. An incident report was filed.

Venous air embolism is an uncommon finding, but carries a mortality rate of more than $20 \% .^{1,2}$ There are various potential causes, including complications of intravenous catheter insertion, trauma or surgery. It is also a possible complication of pressure injection of contrast media, ${ }^{3}$ as was likely the case in this patient. The incidence of venous air embolism is estimated to be as high as $23 \%,{ }^{4}$ although the volume of air required for fatality can be as little as $300 \mathrm{~mL} .{ }^{1}$ Treatment typically consists of hyperbaric oxygen; the patient is placed in the left lateral decubitus position (to decrease air entry into the right ventricular outflow tract), with high-flow oxygen. Paradoxical embolism (crossover from the pulmonary to the systemic circulation) can occur in patients with a patent foramen ovale. ${ }^{5}$ Clinicians should be aware of this risk when ordering imaging with contrast media and determine whether such testing is necessary.

\section{References}

1. Orebaugh SL. Venous air embolism: clinical and experimental considerations. Crit Care Med 1992;20:1169-77.

2. McCarthy CJ, Behravesh S, Naidu SG, et al. Air embolism: practical tips for prevention and treatment. J Clin Med 2016;5. pii:E93.

3. Price DB, Nardi P, Teitcher J. Venous air embolization as a complication of pressure injection of contrast media: CT findings. J Comput Assist Tomogr 1987;11:294-5.

4. Rossi SE, Goodman PC, Franquet T. Nonthrombotic pulmonary emboli. AJR Am J Roentgenol 2000;174:1499-508.

5. Naqvi SY, Sadiq A, Goldberg S. Recurrent paradoxical and pulmonary embolism, hypercoagulable state, and patent foramen ovale. Circulation 2016;133:337-40.

\section{Competing interests: None declared.}

This article has been peer reviewed.

The authors have obtained patient consent.

Affiliations: Department of Emergency Medicine (Fernando); Division of Critical Care (Fernando), Department of Medicine; Division of General Internal Medicine (Munene), Department of Medicine; Department of Radiology (Pena), University of Ottawa, Ottawa, Ont.

Correspondence to: Shannon Fernando, sfernando@toh.ca 